\title{
Inactivation of LACCASE8 and LACCASE5 genes in Brachypodium distachyon leads to severe decrease in lignin content and high increase in saccharification yield without impacting plant integrity
}

Philippe Le Bris ${ }^{1 \dagger}$, Yin Wang ${ }^{1 \dagger}$, Clément Barbereau ${ }^{1}$, Sébastien Antelme ${ }^{1}$, Laurent Cézard ${ }^{1}$, Frédéric Legée ${ }^{1}$, Angelina D'Orlando ${ }^{5}$, Marion Dalmais ${ }^{2,3}$, Abdelhafid Bendahmane ${ }^{2,3}$, Mathias Schuetz ${ }^{4}$, Lacey Samuels ${ }^{4}$, Catherine Lapierre $^{1 *}$ and Richard Sibout ${ }^{1,4,5^{*}}$

\begin{abstract}
Background: Dedicated lignocellulosic feedstock from grass crops for biofuel production is extensively increasing. However, the access to fermentable cell wall sugars by carbohydrate degrading enzymes is impeded by lignins. These complex polymers are made from reactive oxidized monolignols in the cell wall. Little is known about the laccasemediated oxidation of monolignols in grasses, and inactivation of the monolignol polymerization mechanism might be a strategy to increase the yield of fermentable sugars.
\end{abstract}

Results: LACCASE5 and LACCASE8 are inactivated in a Brachypodium double mutant. Relative to the wild type, the lignin content of extract-free mature culms is decreased by $20-30 \%$ and the saccharification yield is increased by $140 \%$. Release of ferulic acid by mild alkaline hydrolysis is also 2.5 -fold higher. Interfascicular fibers are mainly affected while integrity of vascular bundles is not impaired. Interestingly, there is no drastic impact of the double mutation on plant growth.

Conclusion: This work shows that two Brachypodium laccases with clearly identified orthologs in crops are involved in lignification of this model plant. Lignification in interfascicular fibers and metaxylem cells is partly uncoupled in Brachypodium. Orthologs of these laccases are promising targets for improving grass feedstock for cellulosic biofuel production.

Keywords: Laccase, Oxidation, Lignin, Saccharification, Ferulic acid, Grass crop, Fibers, Xylem, Brachypodium

\footnotetext{
*Correspondence: catherine.lapierre@inra.fr; richard.sibout@inra.fr

†Philippe Le Bris and Yin Wang contributed equally to this work

1 Institut Jean-Pierre Bourgin, INRA, AgroParisTech, CNRS, Université Paris-

Saclay, Versailles, France

Full list of author information is available at the end of the article
}

(c) The Author(s) 2019. This article is distributed under the terms of the Creative Commons Attribution 4.0 International License (http://creativecommons.org/licenses/by/4.0/), which permits unrestricted use, distribution, and reproduction in any medium, provided you give appropriate credit to the original author(s) and the source, provide a link to the Creative Commons license, and indicate if changes were made. The Creative Commons Public Domain Dedication waiver (http://creativecommons.org/ publicdomain/zero/1.0/) applies to the data made available in this article, unless otherwise stated. 


\section{Background}

The optimum utilization of plant biomass as an alternative to fossil carbon in order to produce biomolecules, bioenergy and biomaterials is a major challenge for the next decade [1]. Lignocellulose biomass is mainly composed of hemicellulose and cellulose polysaccharides, and phenolic polymers called lignins. It is well established that lignins negatively affect the cellulose-to-ethanol conversion process [2], but lignins also represent potential sources of high-value products [1]. As grasses, such as Miscanthus spp. and switchgrass (Panicum virgatum) are considered promising bioenergy crops, there is increasing interest in their lignin composition and deposition. Lignins are polymerized by the oxidative coupling of $p$-coumaryl, coniferyl and sinapyl alcohols (monolignols), which give rise to $p$-hydroxyphenyl $(\mathrm{H})$, guaiacyl $(\mathrm{G})$ and syringyl (S) units within the lignin polymer, respectively. In addition, lignins formed in grasses (Poaceae) have additional features, the main ones being their association to ferulic acid (FA) and $p$-coumaric acid (CA) [3-8].

The polymerization of monolignols is facilitated by peroxidase and laccase proteins [9]. In planta, the role of laccases in lignification was first revealed in Arabidopsis and poplar plants [10-12]. Less is known about laccases in monocotyledonous plants [13, 14], although recent mutant analyses in Brachypodium distachyon (Brachypodium) have proposed roles in lignification for LACCASE5 (LAC5, Bradi1g66720) and potentially LACCASE6 (LAC6, Bradi1g74320) [15]. While the lignin contents of the mature culms from wild type (WT) and lac6 mutant were similar, the lac5 mutant had a lower lignin content ( 10\% lower) [15]. Considering the limited reductions in the lac5 mutant, we continued to search for additional components that facilitate lignin formation in the model Brachypodium plant. The present study identifies and characterizes the function of LACCASE8 ( $L A C 8$, Bradi2g23370), which has an important function in the lignification of cell walls in Brachypodium distachyon stems.

\section{Results and discussion $\angle A C 5$ and $L A C 8$ are close paralogs with similar expression pattern}

The most recent revision (v3.1) of the Brachypodium accession $B d 21$ genome $[16,17]$ induced changes in position of some LACCASE genes in the genome (Additional file 1) compared to earlier published data [15]. To update our data set and identify new genes involved in lignification, we conducted phylogenetic analysis of the entire Brachypodium laccase family. We used the Blastp tool from Phytozome (https://phytozome.jgi.doe.gov/) to identify homologs of LAC5 (Bradilg66720) in Zea mays,
Oryza sativa and Setaria viridis (Additional file 2). We then selected proteins with the highest e-score $(>50 \%)$ and compared them with laccases published in [15]. We reconstructed a phylogeny tree with the maximum likelihood comparison method (Additional file 3). Despite some names changed for a few laccases (Additional file 1), no major alteration in clusters were found compared with our previous phylogeny analysis [15]. Consistently, LAC5 was most similar to and clustered together with LAC8 and LACCASE12 (LAC12, Bradi2g54740) protein sequences. Considering that the lignin content of the lac5 mutant was found to be only moderately reduced relative to the WT level [15], we hypothesized that another close paralog might be involved in lignification and that its activity might compensate for LAC5 deficiency. We thus analyzed in silico expression levels of the two closest paralogs $L A C 8$ and $L A C 12$ with the Gene Atlas tool from PlaNet (http://aranet.mpimp-golm.mpg. de/ and the BAR Brachypodium eFP Browser (http://bar. utoronto.ca/efp_brachypodium/cgi-bin/efpWeb.cgi) [18]. $L A C 8$ but not $L A C 12$ showed a similar expression pattern with LAC5 (http://bar.utoronto.ca/efp_brachypodium/ cgi-bin/efpWeb.cgi, Fig. 1a). In line with this result, signal values relative to $L A C 8$ and $L A C 5$ transcript levels were both comparable and much higher than those of $L A C 12$ in lignified tissues (Fig. 1a). We verified the expression pattern of $L A C 8$ by qRT-PCR and confirmed data obtained in silico with BAR Brachypodium eFP Browser (Fig. 1b). Indeed, $L A C 8$ is highly expressed in all lignified tissues of Brachypodium (internode, node, peduncle) but poorly detected in developing leaves and young spikelets (Fig. 1b). At last, it is interesting to note that $L A C 6$, $L A C 8, L A C 10$ (Bradi2g54680) but not LAC12 belongs the co-expressed network of $L A C 5$ (Additional file 4). Insofar as $L A C 8$ is a close paralog of $L A C 5$ with a highly similar expression pattern, we hypothesized that $L A C 8$ was most probably involved in cell wall lignification.

\section{Production and characterization of a lac5 lac8 double mutant}

We used the TILLING (Targeting-Induced Local Lesions in Genomes) facility available for Brachypodium at University of Saclay, France (http://www.ips2.u-psud.fr/), to identify lac 8 mutants from a sodium azide mutant collection [19]. Twenty independent lines with mutations in the screened genomic region were isolated using this approach (Fig. 2a). SIFT software analyses revealed which substitutions might partially or totally disrupt the protein activity (Fig. 2a) [19]. By so doing, we selected one homozygous line (line 5731) which harbored an induced stop codon mutation for further analysis. The premature stop codon in this line is predicted to produce a truncated LAC8 protein that lacks the last 29 amino acids of 


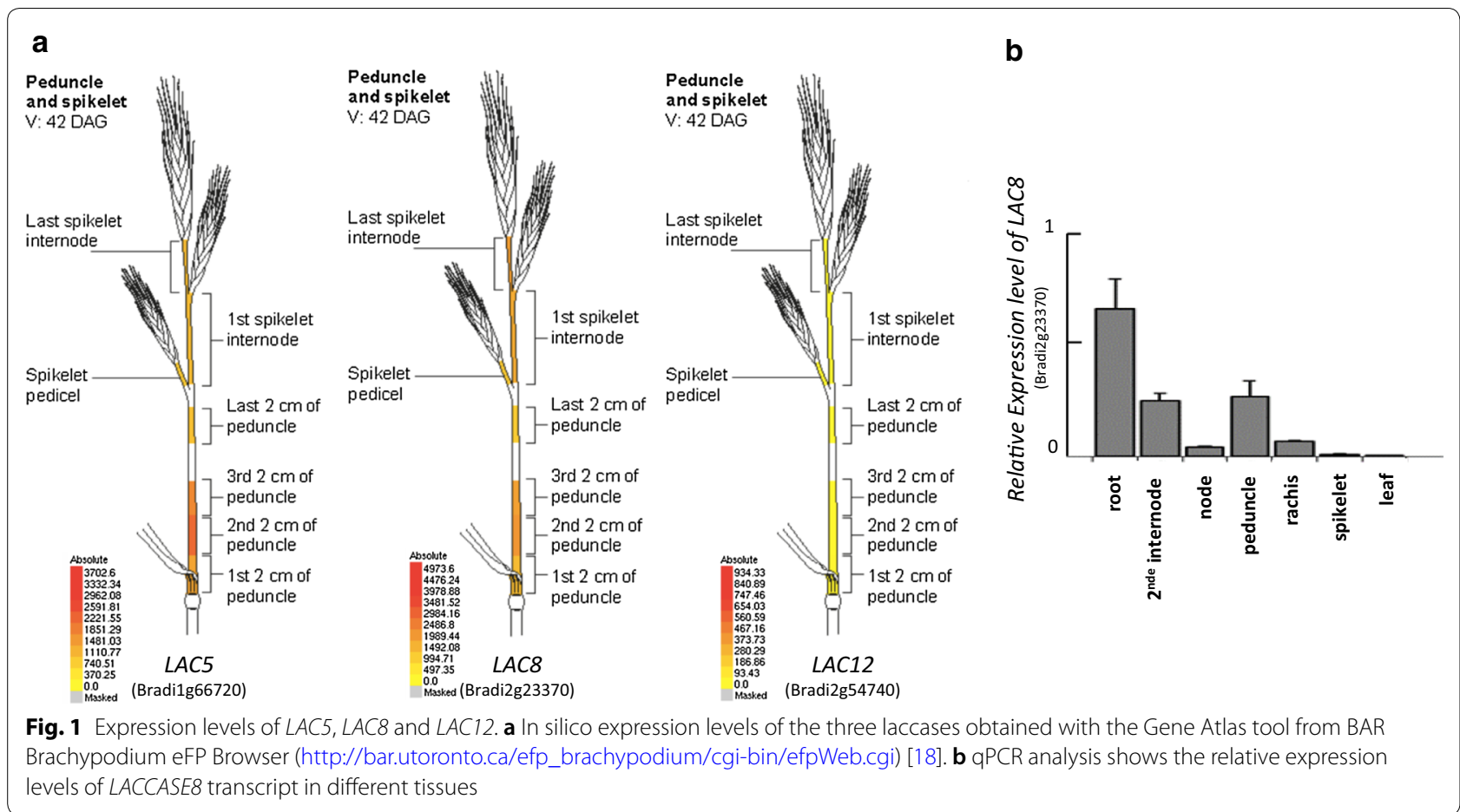

the highly conserved C-terminal region of the LACCASE protein family (Fig. 2b).

To bypass a possible functional genetic redundancy with $L A C 5$ as suggested by both expression patterns of $L A C 5$ and $L A C 8$, we crossed $l a c 8^{5731}$ homozygous line isolated in this study to the previously characterized $l a c 5^{4442}$ homozygous line [15]. We genotyped 136 F2 plants from the resulting F1 generation using highresolution melting (HRM) qPCR. Frequency of both homozygous mutant alleles in F2 progeny revealed a typical 1:16 Mendelian-like segregation. In parallel with HRM qPCR analysis, we generated vibratome cross sections of dried stems from each genotype and performed phloroglucinol- $\mathrm{HCl}$ staining. This staining results in the formation of red stain in the presence of lignified cell walls [20]. Of all genotypes, it was rather obvious that the homozygous lac5 lac8 double mutant $\left(L A C 5^{-} L A C 8^{-}\right.$, Fig. 3) showed the most substantial difference with WT $\left(L A C 5^{++} L A C 8^{++}\right.$, Fig. 3) while this line did not show a severe growth phenotype when cultivated in the greenhouse or in the growth chamber (Fig. 4). UV excitation fluorescence microscopy has also been used as a sensitive method to document the spatial distribution of lignin in cell walls [21, 22]. Using two-photon UV fluorescence microscopy, we clearly observed that fluorescence at $420-460 \mathrm{~nm}$ was impacted in the secondary cell wall of interfascicular fibers (inFF) and mestome (mes) cells in 30-day-old plants (Fig. 5a-d). Surprisingly, fluorescence remained intense inside the fascicular bundle of the double mutant (Fig. 5b). This result suggests that lignins (which emit at 420-460 nm) from protoxylem (pXyl), metaxylem (mXyl) and intrafascicular fibers (FF) are not or moderately impacted. Dried senesced stems (90-dayold plants) treated with phloroglucinol- $\mathrm{HCl}$ confirmed these results (Fig. 5e, f). More importantly, while phloroglucinol-HCl staining was almost undetectable in the secondary cell wall of interfascicular fibers of lac5 lac8, it was still observed in primary cell wall (Fig. $5 \mathrm{~g}$ ). This result is consistent with the observation that some laccases direct lignification in the secondary cell wall [23] but were not localized to the cell corners/middle lamella in Arabidopsis [24]. In lac5 lac8 dried stems, the cell walls of interfascicular fibers were observed to be jagged and malformed probably because of the lack of cell strength and rigidity normally imparted by lignification in WT (Fig. 5h, i). We hypothesize that the lignin polymer functions as a 'cement' in the cell walls of WT plants and in the absence of this cement in the double mutant, the cell wall polysaccharides collapsed in the inner cell space when the plant is dried and cut.

In addition to visible microscopy and two-photon UV fluorescence microscopy, we used Raman spectroscopy to characterize changes in the cell wall composition of interfascicular fibers and metaxylem cells (Fig. 6a). We first compared Raman spectra from mutant versus WT interfascicular fiber cells (Fig. 6b). After baseline 


\begin{tabular}{|c|c|c|c|c|}
\hline $\begin{array}{l}\text { Nucleotide } \\
\text { change and } \\
\text { position }\end{array}$ & $\begin{array}{l}\text { Amino acid } \\
\text { change and } \\
\text { position }\end{array}$ & $\begin{array}{l}\text { Mutation } \\
\text { type }\end{array}$ & Line & $\begin{array}{l}\text { Putative impact on protein } \\
\text { (SIFT score) }\end{array}$ \\
\hline C908A & T303N & Missense & 6243 & $\begin{array}{c}\text { Tolerated Mutation } \\
(0.32)\end{array}$ \\
\hline C956A & S319Y & Missense & 7020 & $\begin{array}{c}\text { Altered Function } \\
(0.05)\end{array}$ \\
\hline C958T & P320S & Missense & 6194 & $\begin{array}{c}\text { Tolerated Mutation } \\
(0.52)\end{array}$ \\
\hline C998T & S333F & Missense & 4854 & $\begin{array}{l}\text { Tolerated Mutation } \\
\qquad(0.10)\end{array}$ \\
\hline C1110T & F370F & Silent & 8416 & \\
\hline C1199T & $\mathrm{S} 400 \mathrm{~F}$ & Missense & 6193 & $\begin{array}{l}\text { Altered Function } \\
(0.00)\end{array}$ \\
\hline C1212T & V404V & Silent & 6827 & \\
\hline G1230A & $\mathrm{K} 410 \mathrm{~K}$ & Silent & 8671 & \\
\hline C1330T & P444S & Missense & 7362 & $\begin{array}{c}\text { Tolerated Mutation } \\
(0.27)\end{array}$ \\
\hline C1388T & T463I & Missense & 12 & $\begin{array}{c}\text { Altered Function } \\
(0.00)\end{array}$ \\
\hline G1436A & S479N & Missense & 5118 & $\begin{array}{l}\text { Tolerated Mutation } \\
(0.69)\end{array}$ \\
\hline G1491A & G497G & Silent & 5846 & \\
\hline C1626T & $\mathrm{H} 542 \mathrm{H}$ & Silent & 145 & \\
\hline G1649A & S550N & Missense & 5000 & $\begin{array}{c}\text { Altered Function } \\
(0.04)\end{array}$ \\
\hline G1653A & W551* & STOP & 5731 & $\begin{array}{c}\text { Altered Function (-- } \\
- \text {-) }\end{array}$ \\
\hline G1666A & A556T & Missense & 6328 & $\begin{array}{c}\text { Altered Function } \\
(0.02)\end{array}$ \\
\hline $\mathrm{C} 1728 \mathrm{~T}$ & I576I & Silent & 5705 & \\
\hline
\end{tabular}

b

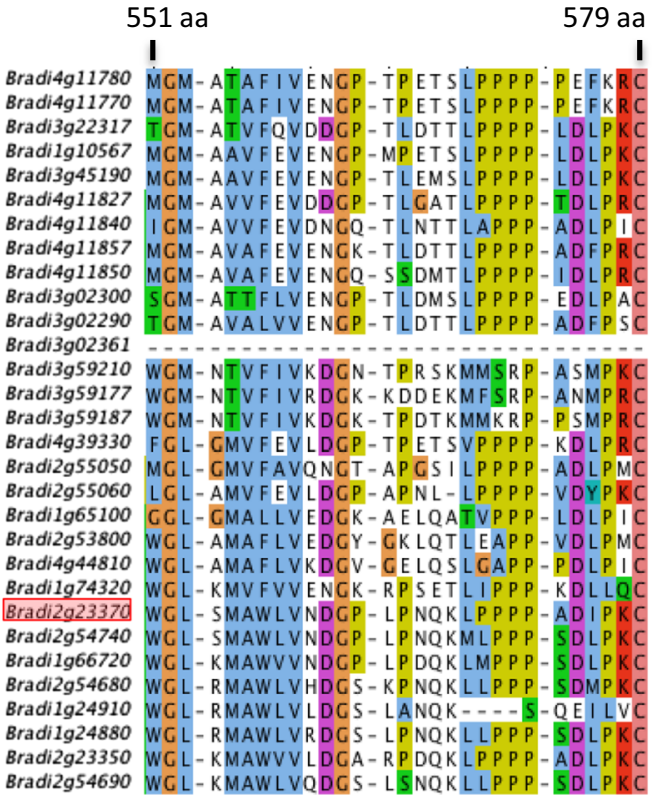

Fig. 2 Allelic series of mutations in LAC8 gene (Bradi2g23370) identified by TILLING and peptide alignment of different Brachypodium laccase C-terminals. a Features of the mutagenized lines identified by TILLING. Lines harboring mutation in non-translated region (intron, $5^{\prime}$ or $3^{\prime} U$ TR) were discarded from the table. $\mathbf{b}$ Alignment of amino acids present in the C-terminal region of all Brachypodium laccases present in the genome of Brachypodium distachyon Bd21-3 accession. The codon encoding tryptophan at position 551 is replaced by a stop codon in the mutant line Bd5731. Colors illustrate the conserved regions between proteins

correction and normalization on standard error, we noticed a substantial decrease in signal at the bands $1171,1203,1268$ and $1337 \mathrm{~cm}^{-1}$ in the double mutant. Interestingly, these bands were attributed to lignin polymers in previous papers. Indeed, based on Raman measurements on standard lignins, $1268 \mathrm{~cm}^{-1}$ has been shown to be specific of G-unit lignin type and $1337 \mathrm{~cm}^{-1}$ has been assigned to both $\mathrm{G}$ and $\mathrm{S}$ units [2528]. The $1203 \mathrm{~cm}^{-1}$ band was assigned to $\mathrm{OCH}_{3}$ present in both $\mathrm{G}$ and $\mathrm{S}$ units $[26,29]$. The $1171 \mathrm{~cm}^{-1}$ band has been assigned to lignins and to esters $(\mathrm{C}-\mathrm{O}-\mathrm{C})$ [30]. Bands at 1603 and $1630 \mathrm{~cm}^{-1}$ were also found slightly changed between mutant and WT. Overall, these signals are often attributed to aromatic compounds and thus to lignin polymers, ferulic and coumaric acids [31, 32].

In the Raman spectroscopy, one new peak at $1370 \mathrm{~cm}^{-1}$ was detected for the lac 5 lac 8 mutant, and signals in the vicinity of 1424 and $1460 \mathrm{~cm}^{-1}$ were also found increased. These bands are attributable to $\mathrm{C}-\mathrm{C}$ and $\mathrm{C}-\mathrm{H}$, and in consequence, it is difficult to assign them to a specific compound in the cell wall, even if they have been often attributed to lignin, cellulose and hemicellulose [30, 32, 33]. Interestingly, when we compared Raman spectra from metaxylem cell walls of WT versus those of double mutant (Fig. 6c), there was no detectable change in intensity of lignin-related peaks (1171, 1203, 1268 and $1337 \mathrm{~cm}^{-1}$ ) despite the fact that we found again a slight 


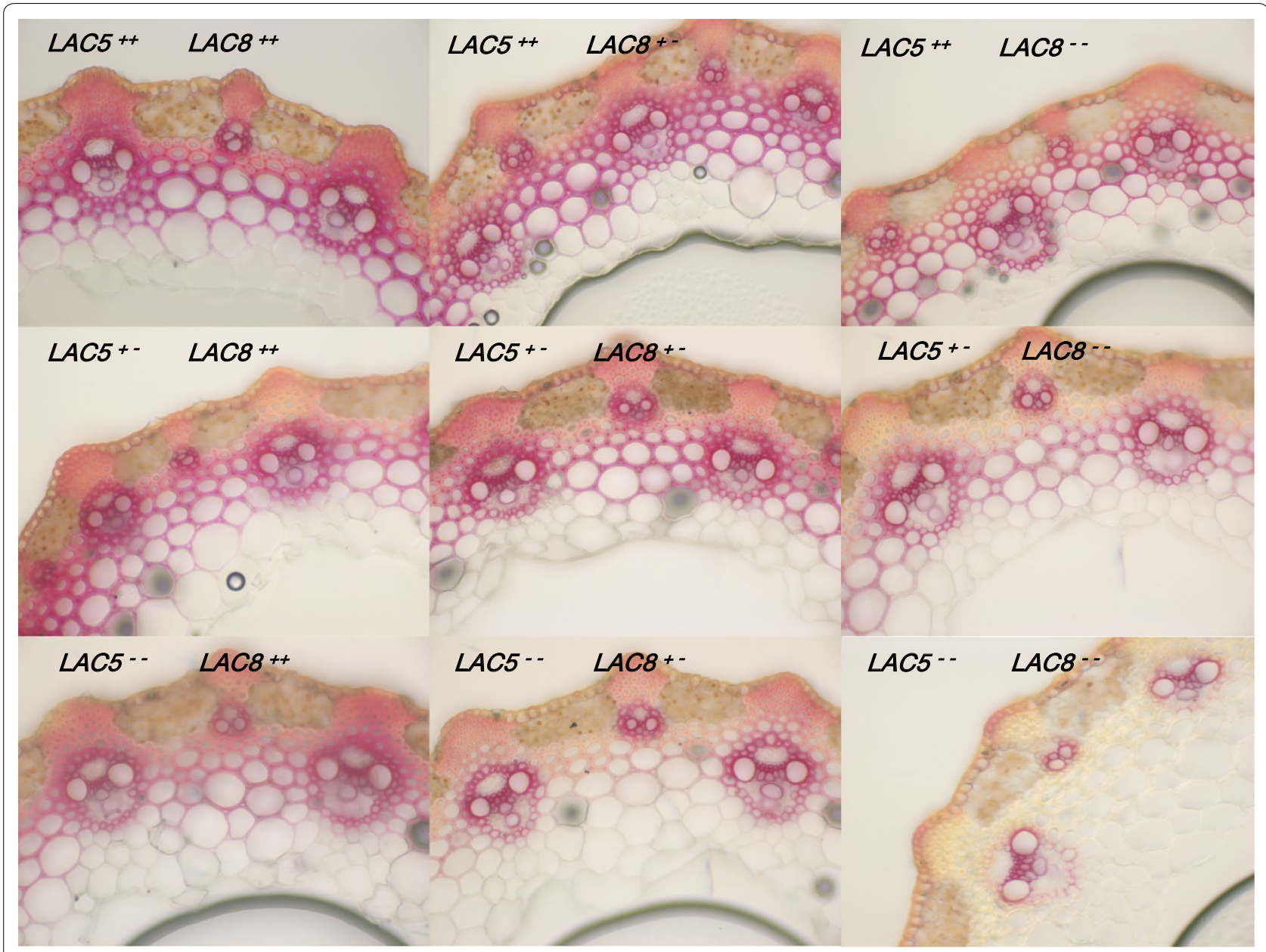

Fig. 3 Lignin patterning in different genotyped mutants. Cross sections of dried stems from F2 plants subjected to phloroglucinol-HCl are imaged. Each genotype respective to mutation in LACCASE5 or LACCASE8 is indicated. ++:WT homozygous, +-: WT heterozygous, --: mutant homozygous

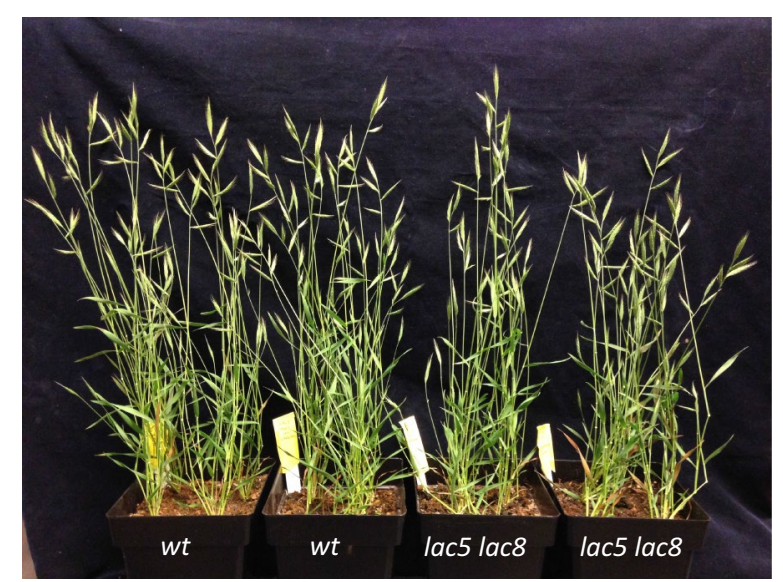

Fig. 4 Growth phenotype of WT and of lac5 lac8 mutant increase in signal in the region of $1330-1460 \mathrm{~cm}^{-1}$. These results confirm that lignification is specifically affected in interfascicular fiber cell wall, but it is not drastically affected in metaxylem cells as suggested by phloroglucinol- $\mathrm{HCl}$ staining and two-photon confocal analysis.

Consistent with the lignin being unaffected in the vessel secondary cell walls, we did not observe collapsed xylem vessels in the Brachypodium lac5 lac8 mutant (Fig. 5g), unlike the Arabidopsis lac4 lac17 double mutant [10] or in Arabidopsis lac4 lac17 lac11 triple mutants [11].

\section{Lignin content and structure are strongly affected in the double lac5 lac8 mutant}

Lignin analyses were performed on single and double mutants along with the WT. Both the gravimetric Klason method and the spectrometric acetyl bromide method confirmed that LAC5 deficiency induced a 

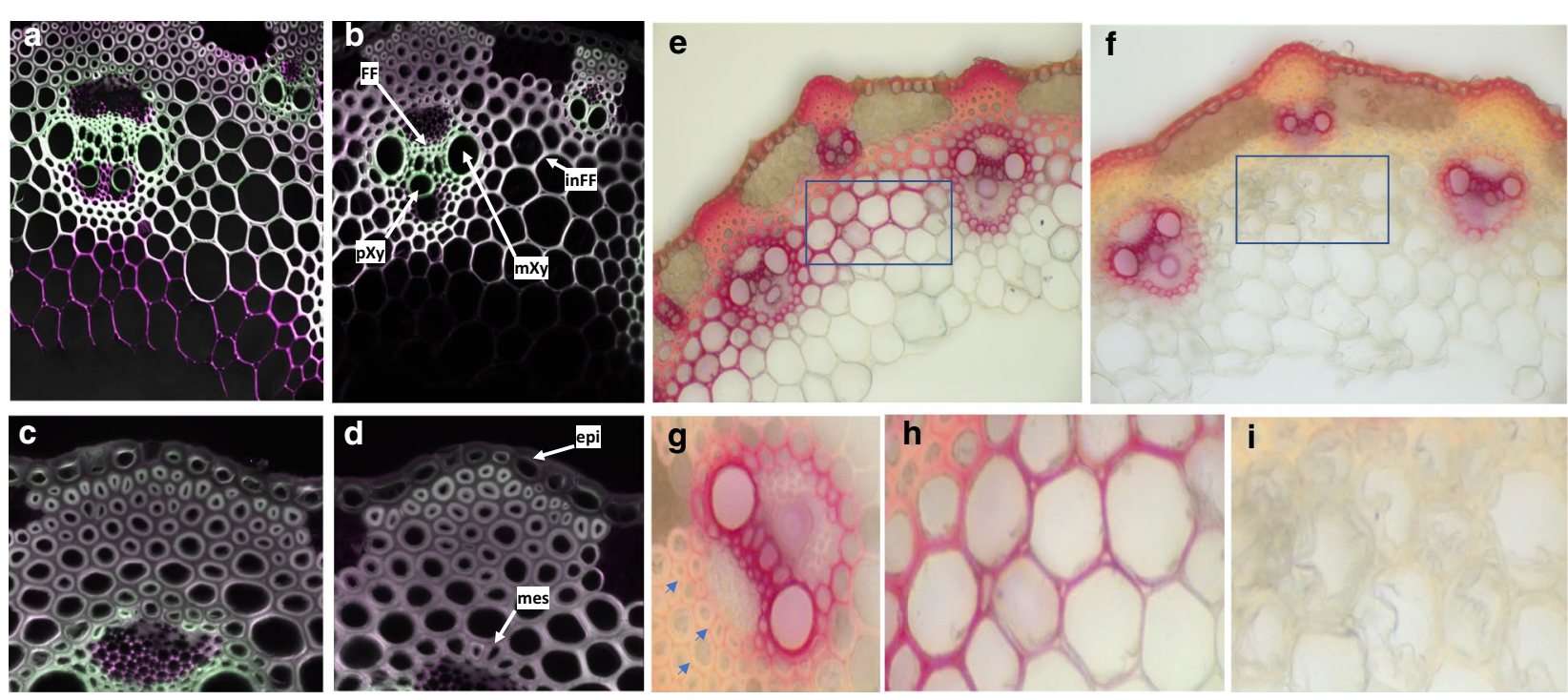

i

Fig. 5 Two-photon fluorescence microscopy imaging and phloroglucinol-HCl staining of WT and lac5 lac8 lignified tissues. Cross sections of 30-day-old plants were imaged using two-photon fluorescence microscopy (green: 420-460-nm emission, purple: 495-540-nm emission a-d) or stained with phloroglucinol-HCl prior imaging under visible microscopy (e-i). WT: a, $\mathbf{c}, \mathbf{e}, \mathbf{h}$; lac5 lac8: $\mathbf{b}, \mathbf{d}, \mathbf{f}, \mathbf{g}$, i. FF intrafascicular fibers, pXy protoxylem, $m X y$ metaxylem, inFF interfascicular fibers, epi epidermis, mes mestome. Blue arrows show red staining of primary cell wall between interfascicular fiber cells in the double mutant
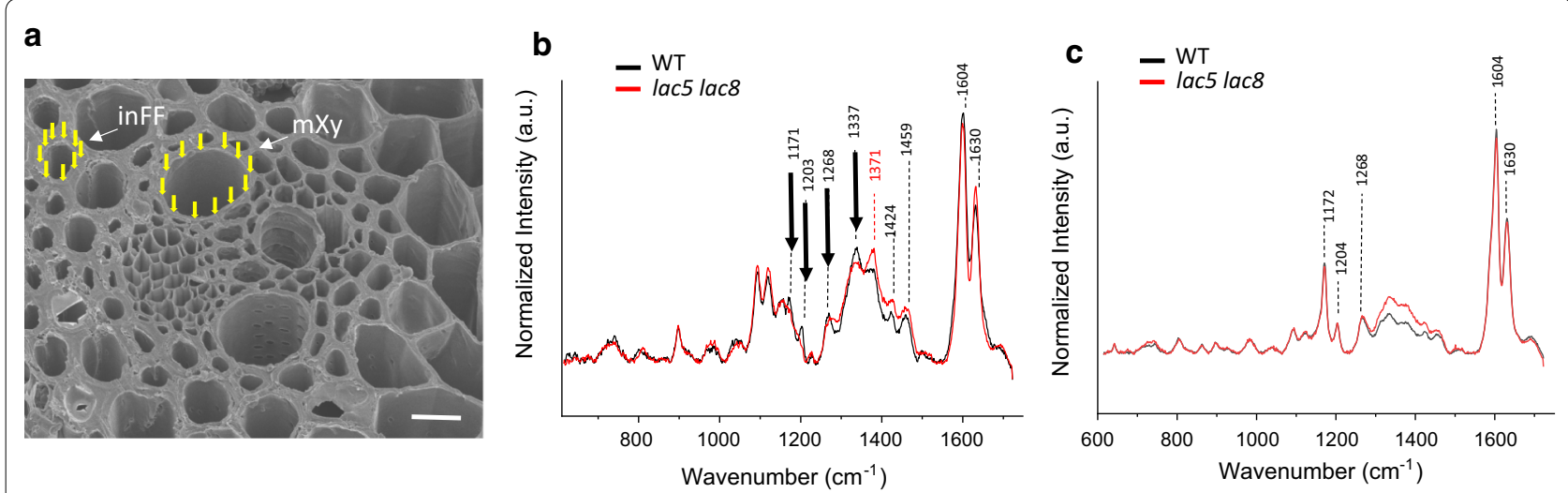

Fig. 6 Raman spectroscopy of interfascicular fiber cell wall and metaxylem cell wall from WT and lac5 lac8. a Scanning electron microscopy of lignified tissues in WT. Yellow arrows illustrate impacts of the laser on cell wall of interfascicular fiber cell and metaxylem. b Raman spectral acquisition of interfascicular fiber cell wall in mutant (red line) and WT (black line). c Raman spectral acquisition of metaxylem cell wall in mutant (red line) and WT (black line). inFF interfascicular fiber, $m X y$ metaxylem. Wavelength numbers for major peaks are indicated

moderate decrease (about 10\%) in the lignin level of Brachypodium mature culms, as compared to WT level (Table 1). A similar decrease (about 10\%) was observed in the lac 8 sample. By contrast, in the lac5 lac 8 double mutant, the lignin level was found to be more severely reduced relative to the WT (20 to $30 \%$, Table 1, [15]). This reduction provides the clue that, together with $L A C 5$, the $L A C 8$ gene is involved in the lignification of Brachypodium stem.
Lignin structure was studied by thioacidolysis. This lignin-specific method provides $p$-hydroxyphenyl $(\mathrm{H})$, guaiacyl (G) and syringyl (S) thioethylated monomers from $\mathrm{H}, \mathrm{G}$ and $\mathrm{S}$ lignin units that are only bound together by $\beta-O-4$ bonds [34]. When expressed relative to the Klason lignin content, thioacidolysis yields were very similar in all samples, which indicates that the proportion of the target $\beta-O-4$ bonds is relatively consistent among the various lines (Table 2). Whatever the 
Table 1 Lignin content of extract-free mature culms from Brachypodium wild type and laccase mutants

\begin{tabular}{lll}
\hline Line & KL \% & ABL \% \\
\hline WT & $18.29 \pm 0.09(100)$ & $20.85 \pm 0.27(100)$ \\
lac5 & $16.37 \pm 0.10(89)^{*}$ & $19.50 \pm 0.50(93)^{*}$ \\
lac8 & $16.52 \pm 0.22(90)^{*}$ & $19.11 \pm 0.42(92)^{*}$ \\
lac5 lac8 & $12.10 \pm 0.04(66)^{*}$ & $16.78 \pm 0.46(80)^{*}$
\end{tabular}

The Klason lignin $(\mathrm{KL})$ and the acetyl bromide lignin $(\mathrm{ABL})$ contents are expressed as weight percentage of extract-free samples. Data are mean values and standard errors from biological triplicates. Values between brackets are the percentages relative to the control level. Asterisks denote significant differences (one-way ANOVA test) relative to the control value at $P<0.05$

Table 2 Determination of the main $\mathrm{H}, \mathrm{G}$ and $\mathrm{S}$ monomers released by thioacidolysis of extract-free mature culms from Brachypodium wild type and laccase mutants

\begin{tabular}{lllll}
\hline Line & $\begin{array}{l}\text { Thioacidolysis yield } \\
(\mathbf{H}+\mathbf{G}+\mathbf{S}) \text { in } \boldsymbol{\mu m o l} / \mathbf{g}\end{array}$ & \multicolumn{4}{l}{ Molar frequency \% } \\
\cline { 3 - 5 } & $\mathbf{K L}$ & \%H & \%G & $\% \mathbf{S}$ \\
\hline WT & $947 \pm 18$ & $3.4 \pm 0.2$ & $33.9 \pm 0.8$ & $62.7 \pm 0.9$ \\
lac5 & $974 \pm 41$ & $2.3 \pm 0.1^{*}$ & $25.7 \pm 1.8^{*}$ & $72.0 \pm 1.9^{*}$ \\
lac8 & $910 \pm 20$ & $2.5 \pm 0.0^{*}$ & $31.4 \pm 0.6^{*}$ & $66.2 \pm 0.6^{*}$ \\
lac5 lac8 & $827 \pm 137$ & $3.4 \pm 0.2$ & $24.8 \pm 1.5^{*}$ & $71.8 \pm 1.5^{*}$ \\
\hline
\end{tabular}

Data are mean values and standard errors from biological triplicates. Asterisks denote significant differences (one-way ANOVA test) relative to the control value at $P<0.05$

sample, $\mathrm{H}$ monomers were recovered as minor components. Relative to the control value, the molar frequency of $\mathrm{G}$ monomers was found to be decreased in all laccase mutants, whereas that of $\mathrm{S}$ monomers was concomitantly increased (Table 2). Not unexpectedly, such opposite variations induced dramatic changes in the S/G molar ratio from 1.85 , for the control, up to 2.90 in lac5 lac8 mutant. These variations reveal that the deposition of G lignin units is more strongly affected in the lac5- and/or lac8deficient mutants. This slight but systematic decrease in G lignin units, already observed in Brachypodium lac5 and Arabidopsis lac17 mutants [10, 15], supports the hypothesis of a spatial and/or temporal specificity of laccase for coniferyl alcohol. These laccases could be more active during the early lignification stages when $G$ units are specifically deposited prior to $\mathrm{S}$ units [35].

The amount of CA and FA ester-linked to Brachypodium cell walls was measured by mild alkaline hydrolysis. It is now well established that, in grass lignified tissues, most CA esters are linked to lignins while a lower amount is ester-linked to the arabinose substituents of arabinoxylans [36]. The amount of lignin-associated CA esters was reduced in the double mutant (Table 3), a phenomenon that could be related to its lower lignin content. Cell wall FA esters are predominantly linked to the
Table 3 Determination of $p$-coumaric acid (CA) and ferulic acid (FA) released by mild alkaline hydrolysis of extractfree mature culms from Brachypodium wild type and laccase mutants

\begin{tabular}{llc}
\hline Line & CA $\mathbf{~} \mathbf{g} / \mathbf{g}$ & FA $\mathbf{~ m} \mathbf{~} \mathbf{g}$ \\
\hline WT & $6.01 \pm 0.22$ & $5.24 \pm 0.26$ \\
lac5 & $5.71 \pm 0.51$ & $7.86 \pm 0.18^{*}$ \\
lac8 & $5.08 \pm 0.19^{*}$ & $5.88 \pm 0.03^{*}$ \\
lac5 lac8 & $4.81 \pm 0.39^{*}$ & $12.99 \pm 0.50^{*}$ \\
\hline
\end{tabular}

Data are mean values and standard errors from biological triplicates. Asterisks denote significant differences (one-way ANOVA test) relative to the control value at $P<0.05$

arabinose substituents of arabinoxylans. These FA esters are proposed to act as initiation sites for lignification as first revealed by the identification of FA ether-linked to a $\mathrm{G}$ unit [8]. These oxidatively driven and resistant linkages between FA esters and lignins reduce the FA recovery after mild alkaline hydrolysis. On this basis, the dramatic increase in alkali-releasable FA from the double mutant may be directly related to its substantially lower lignin content.

Because the drastic decrease in lignin content may deeply impact the cell wall's susceptibility to enzymatic digestion, we performed saccharification assays without pre-treatment. Saccharification efficiency was evaluated both by the weight loss induced by the cellulose hydrolysis treatment and by the amount of glucose released in the reaction medium. As revealed in Table 4, saccharification efficiency was slightly increased in the single lac5 mutant, whereas it was not changed in the lac 8 sample. By contrast and consistent with the severely reduced lignin content, this saccharification efficiency was substantially increased from the biomass of the lac5 lac8 double mutant (Table 4).

\section{Conclusion}

This work provides the first demonstration that $L A C 8$ gene is involved in the lignification of Brachypodium culm. The impact of loss of function of LAC5 and LAC8 was specifically on the interfascicular fiber cells, which make up the bulk of the grass stem. This was reflected in the substantial increased saccharification yield of the double mutant lines. Cytology studies and Raman spectroscopy showed that lignification of metaxylem cells is not or only slightly impacted in lac5 lac 8 double mutant, which permits these double mutants to continue to grow relatively normally. This result suggests that vascular tissues produce other enzymes that balance the loss of activity of LAC5 and LAC8. At last, close orthologs of the Brachypodium $L A C 5$ and $L A C 8$ genes are clearly 
Table 4 Saccharification assays of extractive-free mature stem from Brachypodium wild type and laccase mutants

\begin{tabular}{llc}
\hline Genotype & Weight loss percentage & Glucose $\mathbf{( \mathbf { m g ~ g } ^ { - \mathbf { 1 } } )}$ \\
\hline WT & $22.4 \pm 1.3$ & $67.4 \pm 2.6$ \\
lac5 & $28.1 \pm 1.3^{*}$ & $97.9 \pm 5.8^{*}$ \\
lac8 & $20.4 \pm 1.0$ & $64.7 \pm 0.4$ \\
lac5 lac8 & $48.8 \pm 0.9^{*}$ & $160.1 \pm 26.8^{*}$ \\
\hline
\end{tabular}

Saccharification is evaluated both by the weight loss percentage and by the amount of glucose released from the samples

The data represent mean values and standard deviation from 3 to 4 biological replicates. Asterisks denote significant differences analyzed by one-way ANOVA (Tukey's HSD, $P<0.05$ )

identifiable in the genome of maize or rice, which confirms that these laccase genes are both promising targets to genetically redesign grass cell walls with improved susceptibility to enzymatic hydrolysis.

\section{Materials and methods}

\section{Plant material and growth conditions}

Single mutants were selected by TILLING in the collection of chemically induced Brachypodium mutants as described in [19]. lac5 (line 4442) and lac8 (line 5731) were generated by selfing the initial tilled lines. Brachypodium plants (accession $B d 21-3$ ) were grown in a greenhouse under long-day conditions (18-h light, 400-W sodium lamps). Day and night temperatures were $23{ }^{\circ} \mathrm{C}$ and $18{ }^{\circ} \mathrm{C}$, respectively.

\section{Histochemical staining}

All the histochemical staining was performed on sections cut in the middle of the second internode from the top. Samples were hand-sectioned or embedded in $7 \%$ agarose before being transversely sectioned at a thickness of $50 \mu \mathrm{m}$ using a vibratome (Leica VT1000S, Leica, Germany). Lignin deposition and composition were investigated histochemically by Wiesner staining (Phloroglucinol- $\mathrm{HCl}$ ) as previously published [20]. All sections were observed under a Zeiss AxioPlan 2 microscope system with automatic exposure times.

\section{TILLING and sequence analysis}

PCR amplification and detection of mutations DNA amplification are based on nested PCR. The first PCR amplification is a standard PCR with target-specific primers and 10 ng of Brachypodium genomic DNA. Forward primer LCZ23_N1F1: CGCAGTCGCCAACCA CACGCTGACGG and reverse primer LCZ23_N1R1: CGTGCAACACCATCGACCCATTCAGC were used. One milliliter of the first PCR product served as a template for the second nested PCR amplification, with a combination of specific primers carrying M13 tail and
M13 universal primers, M13F700 (59-CACGACGTT GTAAAACGAC-39) and M13R800 (59-GGATAACAT TTCACACAGG-39), labeled at the $5^{\prime}$ end with infrared dyes IRD700 and IRD800 (LI-CORH, Lincoln, Nebraska, USA), respectively. Mutation detection was carried out as described previously except for the second PCR. This PCR was carried out using $0.05 \mathrm{mM}$ of specific primers carrying M13 tail and $0.1 \mathrm{mM}$ of M13 universal primers. The identity of the mutations was determined by sequencing. Sequence analysis was performed with CODDLE software (Codons Optimized to Discover Deleterious Lesions) [37] and PARSESNP software [38]. Prediction of the impact of each mutation was made with SIFT software [39] as described in [19]. Multiple sequence alignment of full-length protein sequences was performed with ClustalW software (http://www.ebi. ac.uk/Tools/clustalw2).

\section{Lignin content and structure determination}

All main stems of each plant were collected and ground after removing spikelets and leaves. Ground samples were sequentially extracted at $60{ }^{\circ} \mathrm{C}$ with $50 \mathrm{~mL}$ of ethanol, water and ethanol. At each step, the samples were vortexed. These steps were repeated twice before sample drying. The extracted and dried samples, referred to as extract-free samples, were used for lignin analyses.

Lignin content was measured by the Klason method and the acetyl bromide method according to [40]. Lignin structure was studied by thioacidolysis, as previously described [41]. The lignin-derived thioacidolysis monomers were identified by gas chromatography-mass spectrometry as their trimethylsilylated derivatives. All the analyses were performed with at least three biological replicates. Significant differences were inferred by oneway ANOVA (Tukey's HSD, $P<0.05$ ).

\section{PCR high-resolution melting (HRM) and quantitative PCR}

Approximately $20 \mathrm{ng}$ of leaf DNA extract was subjected to PCR amplification on Eppendorf Realplex2 Mastercycler using the SYBR Green kit (Bio-Rad) and using the following conditions: $95^{\circ} \mathrm{C}$ for $5 \mathrm{~min}$, followed by 45 cycles of $95^{\circ} \mathrm{C}$ for $30 \mathrm{~s}, 62^{\circ} \mathrm{C}$ for $30 \mathrm{~s}$ and $72{ }^{\circ} \mathrm{C}$ for $30 \mathrm{~s}$. Amplifications were made with the following primers: LAC5fw-CCGGAGGTTGGGTCGCCATCAGGTT and LAC5rev-CATTTACGGTTAAGCAAGAACGTGTGC ACG for LACCASE5 (Bradilg66320); LAC8fw-GGG CATGCAGGTGTATGGAT and LAC8rev-CGGCAA CTTCTGGTTCGGTA for LACCASE8 (Bradi2g23370). A high melting curve program was used to detect the different alleles with the following program: $95^{\circ} \mathrm{C}$ for $10 \mathrm{~s}$, $65{ }^{\circ} \mathrm{C}$ for $5 \mathrm{~s}$ and increase of $0.2{ }^{\circ} \mathrm{C}$ every $5 \mathrm{~s}$ until $95^{\circ} \mathrm{C}$. Fluorescence was quantified every $5 \mathrm{~s}$. Relative expression of $L A C 8$ was quantified as described in [15] using 
the following primers: qLAC8-fw-TACACGTTCAAT GTGACAATGGCG and qLAC8-rev CTCACGCCG TGCCAGTGGAAG.

\section{Phylogeny tree}

An unrooted phylogenetic tree was reconstructed with PhyML in the Phylogeny.fr platform (http://www.phylo geny.fr) [42]. Sequences were aligned with MUSCLE (V3.8.31) and then corrected with Gblocks (V0.91b). The phylogenetic tree was reconstructed using the maximum likelihood method implemented in the PhyML program (v3.1/3.0 aLRT) and graphically edited using TreeDyn (v198.3). Protein homologs from Brachypodium, rice, maize and Setaria were identified and downloaded from Phytozome V.12.1 (https://phytozome.jgi.doe.gov/).

\section{Cell wall saccharification}

Saccharification assays were performed as described by [10]. For each sample, $30 \mathrm{mg}$ of extract-free samples was incubated with $4 \mathrm{~mL}$ of acetate buffer $\mathrm{pH} 4.5$, containing $4 \mathrm{mg} / \mathrm{mL}$ commercial cellulase (cellulase OnozukaR10; Serva) and $0.5 \mathrm{mg} / \mathrm{mL} \mathrm{NaN}_{3}$ for 3 days at $45{ }^{\circ} \mathrm{C}$ on a carousel. After centrifugation, the glucose content of the supernatant was determined via enzymatic assay with the bioMérieux Kit (bioMérieux, Craponne, France). The pellet was washed twice with water, then freeze-dried and weighed to evaluate the weight loss.

\section{Raman spectroscopy}

Forty-micrometer sections of internodes were cut using a vibratome (HM $650 \mathrm{~V}$, Microm Microtech), then placed with a drop of water on an aluminum slide and sealed with a coverslip and nail polish. Raman spectra were recorded using a microconfocal Raman inVia Reflex (Renishaw), equipped with a double-edge filter to eliminate the Rayleigh scattering with a cut at $100 \mathrm{~cm}^{-1}$, three wavelengths $(532 \mathrm{~nm}, 633 \mathrm{~nm}$ and $785 \mathrm{~nm})$ and two used different gratings $(1800$ and $1200 \mathrm{~L} / \mathrm{mm})$. The setup consisted of a confocal microscope aligned with an automated XYZ table, where the displacement motors generated $100 \mathrm{~nm}$ steps. Then, the focused power of the laser beam was checked for each wavelength to avoid any transformation or heating of the samples. The spectral resolution was smaller than $4 \mathrm{~cm}^{-1}$ with a precision better than $0.5 \mathrm{~cm}^{-1}$. Several Raman measurements were taken in secondary cell walls of metaxylem cell and sclerenchyma. Three to five biological repetitions per genotype were analyzed. A total of 20-30 measurements were taken for each cell type (metaxylem cell or sclerenchyma). Cosmic ray removal was applied using $4.2 \mathrm{Wire}$ software (Renishaw), and spectra were further analyzed using OriginLab Pro software. An average spectrum was obtained for each region of interest, which was baselinecorrected and normalized.

\section{Scanning electron microscopy (SEM)}

Two-millimeter hand-cross sections of 30-day-old WT stems were spray-coated with cobalt using a Cressington 208HR High Resolution Sputter Coater and observed with a Hitachi S-4700 field emission SEM.

\section{Two-photon fluorescence microscopy}

An Olympus FV1000 Multiphoton Laser Scanning Microscope with a tunable MaiTai BB DeepSee $(710-990 \mathrm{~nm})$ laser was used to stimulate lignin autofluorescence. Excitation ( 350 to $370 \mathrm{~nm}$ ) of lignin autofluorescence is achieved by the absorption of two 730-nm photons [43]. During imaging, two emission channels (420-460 nm and 495-540 nm) are simultaneously collected. Samples were imaged using the Olympus XL Plan N25X objective.

\section{Additional files}

Additional file 1. The laccase protein family in the sequenced Bd21 natural accession. Laccase proteins published in [15] are listed with their respective name regarding the first version (V1.0) or the most recent version (V3.1) of the Bd21 genome sequence.

Additional file 2. Predicted LACCASE proteins in Brachypodium, maize, rice and Setaria. Putative laccases protein sequences of Zea mays, Oryza sativa, Setaria viridis and Brachypodium distachyon were obtained from proteomic databases available on Phytozome (https://phytozome.jgi.doe. gov/pz/portal.html).

Additional file 3. Phylogeny tree reconstructed with Brachypodium, maize, rice and Setaria LACCASES. The phylogenetic tree was reconstructed using the maximum likelihood method implemented in the PhyML program. The putative proteins sequences used to reconstruct the tree are available in Additional files 1 and 2. Branch length is proportional to the number of substitutions per site and represents evolutionary distance as indicated by the scale bar. The colored cluster highlights the positions of LACCASE 5 and 8 and their closest orthologs in other species.

Additional file 4. Genes co-expressed with LAC5 (LAC8 is in bold red). The table containing genes found in the co-expression network was made with the search tool from PlaNet (http://www.gene2function.de/) using LAC5 gene (Brad1g66720) as a bait.

\section{Acknowledgements}

We thank Anne-Laure Chateigner-Boutin for reading the manuscript. We also acknowledge Sylvie Durand for interesting discussions about Raman experiments. We thank Sebastien Santini for making available the site Phylogeny.fr. SEM picture of Brachypodium stem was made thanks to the UBC Bioimaging Facility www.bioimaging.ubc.ca.

\section{Authors' contributions}

RS supervised the study, designed experiments, performed experiments, analyzed data, prepared figures and cowrote the manuscript. CL performed experiments, analyzed data, prepared tables and cowrote the manuscript. LS an MS performed experiments, analyzed data and edited the manuscript. MD and $A B$ performed TILLING experiments. SA cultivated plants and selected genotypes. ADO analyzed Raman data and prepared figures. LC and FL 
performed lignin analyses. PLB, YW and CB genotyped and characterized mutants. All authors read and approved the final manuscript.

\section{Funding}

This work was funded by INRA, Agreenskills program (European Union's 7th Framework Programme for research, technological development and demonstration under Grant Agreement Numbers FP7-267196 and FP7-609398, and INRA) and the Agence Nationale de la Recherche (ANR-14-CE19-0012-01) project. The IJPB benefits from the support of the LabEx Saclay Plant SciencesSPS (ANR-10-LABX-0040-SPS).

\section{Availability of data and materials}

All data generated or analyzed during this study are included in the published article and its Additional files. Materials are available from the corresponding authors.

\section{Ethics approval and consent to participate}

Not applicable.

\section{Consent for publication}

Not applicable.

\section{Competing interests}

The authors declare that they have no competing interests.

\section{Author details}

${ }^{1}$ Institut Jean-Pierre Bourgin, INRA, AgroParisTech, CNRS, Université ParisSaclay, Versailles, France. ${ }^{2}$ Institute of Plant Sciences Paris Saclay IPS2, CNRS, INRA, Université Paris-Sud, Université Evry, Université Paris-Saclay, Batiment 630,91405 Orsay, France. ${ }^{3}$ Institute of Plant Sciences Paris-Saclay IPS2, Paris Diderot, Sorbonne Paris-Cité, Bâtiment 630, 91405 Orsay, France. ${ }^{4}$ Department of Botany, University of British Columbia, Vancouver, BC V6T 1Z4, Canada. ${ }^{5}$ UR1268 BIA (Biopolymères Interactions Assemblages), INRA, 44300 Nantes, France.

Received: 20 March 2019 Accepted: 7 July 2019

Published online: 15 July 2019

\section{References}

1. Ragauskas AJ, Williams CK, Davison BH, Britovsek G, Cairney J, Eckert CA, et al. The path forward for biofuels and biomaterials. Science. 2006;311(5760):484-9.

2. Wang $Y$, Chantreau M, Sibout R, Hawkins S. Plant cell wall lignification and monolignol metabolism. Front Plant Sci. 2013:4:220.

3. Ralph J, Hatfield RD, Quideau S, Helm RF, Grabber JH, Jung HJG. Pathway of $p$-coumaric acid incorporation into maize lignin as revealed by NMR. J Am Chem Soc. 1994;116(21):9448-56.

4. Ralph JQS, Grabber JH, Hatfield RD. Identification and synthesis of new ferulic acid dehydrodimers present in grass cell walls. J Chem Soc Perkin Trans. 1994;1:3485-98.

5. Grabber JH, Quideau S, Ralph J. p-coumaroylated syringyl units in maize lignin: implications for beta-ether cleavage by thioacidolysis. Phytochemistry. 1996;43(6):1189-94.

6. Ralph J. Hydroxycinnamates in lignification. Phytochem Rev. 2010;9(1):65-83.

7. Karlen SD, Zhang C, Peck ML, Smith RA, Padmakshan D, Helmich KE, et al. Monolignol ferulate conjugates are naturally incorporated into plant lignins. Sci Adv. 2016;2(10):e1600393.

8. Jacquet G, Pollet B, Lapierre C, Mhamdi F, Rolando C. New ether-linked ferulic acid-coniferyl alcohol dimers identified in grass cell walls. J Agric Food Chem. 1995;43:2746-51.

9. Vanholme R, Morreel K, Darrah C, Oyarce P, Grabber JH, Ralph J, et al Metabolic engineering of novel lignin in biomass crops. New Phytol. 2012;196(4):978-1000.

10. Berthet S, Demont-Caulet N, Pollet B, Bidzinski P, Cézard L, Le Bris P, et al. Disruption of LACCASE4 and 17 results in tissue-specific alterations to lignification of Arabidopsis thaliana stems. Plant Cell. 2011;23(3):1124-37.
11. Zhao Q, Nakashima J, Chen F, Yin Y, Fu C, Yun J, et al. Laccase is necessary and nonredundant with peroxidase for lignin polymerization during vascular development in Arabidopsis. Plant Cell. 2013;25(10):3976-87.

12. Lu S, Li Q, Wei H, Chang MJ, Tunlaya-Anukit S, Kim H, et al. Ptr-miR397a is a negative regulator of laccase genes affecting lignin content in Populus trichocarpa. Proc Natl Acad Sci USA. 2013;110(26):10848-53.

13. Cesarino I, Araujo P, Sampaio Mayer JL, Vicentini R, Berthet S, Demedts $B$, et al. Expression of SofLAC, a new laccase in sugarcane, restores lignin content but not S:G ratio of Arabidopsis lac17 mutant. J Exp Bot. 2013;64(6):1769-81.

14. Wang J, Feng J, Jia W, Fan P, Bao H, Li S, et al. Genome-wide identification of sorghum bicolor laccases reveals potential targets for lignin modification. Front Plant Sci. 2017;8:714.

15. Wang Y, Bouchabke-Coussa O, Le Bris P, Antelme S, Soulhat C, Gineau E, et al. LACCASE 5 is required for lignification of the Brachypodium distachyon culm. Plant Physiol. 2015;168(1):192-204.

16. Gordon SP, Contreras-Moreira B, Woods DP, Des Marais DL, Burgess D, Shu $\mathrm{S}$, et al. Extensive gene content variation in the Brachypodium distachyon pan-genome correlates with population structure. Nat Commun. 2017:8(1):2184

17. Initiative TIB. Genome sequencing and analysis of the model grass Brachypodium distachyon. Nature. 2010;463(7282):763-8.

18. Sibout R, Proost S, Hansen BO, Vaid N, Giorgi FM, Ho-Yue-Kuang S, et al. Expression atlas and comparative coexpression network analyses reveal important genes involved in the formation of lignified cell wall in Brachypodium distachyon. New Phytol. 2017;215(3):1009-25.

19. Dalmais M, Antelme S, Ho-Yue-Kuang S, Wang Y, Darraca O, Bouvier d'Yvoire M, et al. A TILLING platform for functional genomics in Brachypodium distachyon. PLoS ONE. 2013;8(6):e65503.

20. Bouvier d'Yvoire M, Bouchabke-Coussa O, Voorend W, Antelme S, Cezard $L$, Legee $F$, et al. Disrupting the cinnamyl alcohol dehydrogenase 1 gene (BdCAD1) leads to altered lignification and improved saccharification in Brachypodium distachyon. Plant J. 2013;73(3):496-508.

21. Donaldson LA, Knox JP. Localization of cell wall polysaccharides in normal and compression wood of radiata pine: relationships with lignification and microfibril orientation. Plant Physiol. 2012;158(2):642-53.

22. Donaldson L, Vaidya A. Visualising recalcitrance by colocalisation of cellulase, lignin and cellulose in pretreated pine biomass using fluorescence microscopy. Sci Rep. 2017;7:44386

23. Schuetz M, Benske A, Smith RA, Watanabe Y, Tobimatsu Y, Ralph J, et al. Laccases direct lignification in the discrete secondary cell wall domains of protoxylem. Plant Physiol. 2014;166(2):798-807.

24. Yi Chou E, Schuetz M, Hoffmann N, Watanabe Y, Sibout R, Samuels AL. Distribution, mobility, and anchoring of lignin-related oxidative enzymes in Arabidopsis secondary cell walls. J Exp Bot. 2018;69(8):1849-59.

25. Agarwal U, Terashima N. FT-Raman study of dehydrogenation polymer (DHP) lignins. In:12th ISWPC international symposium on wood and pulping chemistry: Madison, Wisconsin, USA, June 9-12, 2003: proceedings, volume III : poster presentations. Madison, WI : University of WisconsinMadison, Dept. of Forest Ecology and Management, 2003. p. 123-6.

26. Larsen KL, Barsberg S. Theoretical and Raman spectroscopic studies of phenolic lignin model monomers. J Phys Chem B. 2010;114(23):8009-21.

27. Sun L, Varanasi P, Yang F, Loque D, Simmons BA, Singh S. Rapid determination of syringyl: guaiacyl ratios using FT-Raman spectroscopy. Biotechnol Bioeng. 2011;109(3):647-56.

28. Agarwal UP, McSweeny JD, Ralph SA. FT-Raman investigation of milledwood lignins: softwood, hardwood, and chemically modified black spruce lignins. J Wood Chem Technol. 2011;31(4):324-44

29. Agarwal UP, Kawai N. Self-absorption phenomenon in near-infrared Fourier transform Raman spectroscopy of cellulosic and lignocellulosic materials. Appl Spectrosc. 2005;59(3):385-8.

30. Wiley J, Atalla R. Band assignments in the raman spectra of celluloses. Carbohydr Res. 1987;160:113-29.

31. Ozparpucu M, Gierlinger N, Burgert I, Van Acker R, Vanholme R, Boerjan $W$, et al. The effect of altered lignin composition on mechanical properties of cinnamyl alcohol dehydrogenase (CAD) deficient poplars. Planta. 2018;247(4):887-97.

32. Sene CFB, McCann MC, Wilson RH, Grinter R. Fourier-transform Raman and Fourier-transform infrared spectroscopy (an investigation of five higher plant cell walls and their components). Plant Physiol. 1994;106(4):1623-31. 
33. Kačuráková M, Wellner N, Ebringerová A, Hromádková Z, Wilson RH, Belton PS. Characterisation of xylan-type polysaccharides and associated cell wall components by FT-IR and FT-Raman spectroscopies. Food Hydrocolloids. 1999;13(1):35-41.

34. Lapierre C. Determining lignin structure by chemical degradations. In: Heitner C, Dimmel D, Schmidt JA, editors. Lignin and lignans-advances in chemistry. Boca Raton: CRC Press, Taylor \& Francis Group; 2010. p. 11-48.

35. Terashima N, Fukushima K. Comprehensive model of the lignified plant cell wall. In: Jung HG, Buxton DR, Hatfield RD, Ralph R, editors. Forage cell wall structure and digestibility. Madison: American Society of Agronomy; 1993. p. 247-70

36. Hatfield RD, Rancour DM, Marita JM. Grass cell walls: a story of crosslinking. Front Plant Sci. 2016;7:2056.

37. Till BJ, Reynolds SH, Greene EA, Codomo CA, Enns LC, Johnson JE, et al. Large-scale discovery of induced point mutations with high-throughput TILLING. Genome Res. 2003;13(3):524-30.

38. Taylor NE, Greene EA. PARSESNP: a tool for the analysis of nucleotide polymorphisms. Nucleic Acids Res. 2003;31(13):3808-11.
39. Ng PC, Henikoff S. Predicting deleterious amino acid substitutions. Genome Res. 2001;11(5):863-74.

40. Dence CW. The determination of lignin. In: Lin SY, Dence CW, editors. Methods in lignin chemistry. Springer: Berlin; 1992. p. 33-61.

41. Lapierre C, Pollet B, Petit-Conil M, Toval G, Romero J, Pilate G, et al. Structural alterations of lignins in transgenic poplars with depressed cinnamyl alcohol dehydrogenase or caffeic acid O-methyltransferase activity have an opposite impact on the efficiency of industrial kraft pulping. Plant Physiol. 1999;119(1):153-63.

42. Dereeper A, Audic S, Claverie JM, Blanc G. BLAST-EXPLORER helps you building datasets for phylogenetic analysis. BMC Evol Biol. 2010;10:8.

43. Zipfel WR, Williams RM, Webb WW. Nonlinear magic: multiphoton microscopy in the biosciences. Nat Biotechnol. 2003;21(11):1369-77.

\section{Publisher's Note}

Springer Nature remains neutral with regard to jurisdictional claims in published maps and institutional affiliations.
Ready to submit your research? Choose BMC and benefit from:

- fast, convenient online submission

- thorough peer review by experienced researchers in your field

- rapid publication on acceptance

- support for research data, including large and complex data types

- gold Open Access which fosters wider collaboration and increased citations

- maximum visibility for your research: over 100M website views per year

At BMC, research is always in progress.

Learn more biomedcentral.com/submissions 